\title{
Analysis on Energy Efficiency in Healthcare Buildings
}

\author{
Justo García-Sanz-Calcedo \\ Department of Mechanical and Energetic Engineering, Extremadura University, \\ Badajoz, Spain
}

Submitted November 2013. Accepted for publication May 2014.

\begin{abstract}
The aim of this paper is to analyze and quantify the average healthcare centres' energy behavior and estimate the possibilities of savings through the use of concrete measures to reduce their energy demand in Extremadura, Spain. It provides the average energy consumption of 55 healthcare centres sized between 500 and $3,500 \mathrm{~m}^{2}$. The analysis evaluated data of electricity and fossil fuel energy consumption as well as water use and other energy-consuming devices. The energy solutions proposed to improve the efficiency are quantified and listed. The average annual energy consumption of a healthcare centre is $86.01 \mathrm{kWh} / \mathrm{m}^{2}$, with a standard deviation of $16.8 \mathrm{kWh} / \mathrm{m}^{2}$. The results show that an annual savings of $€ 4.77 / \mathrm{m}^{2}$ is possible. The potential to reduce the energy consumption of a healthcare centre of size $1,000 \mathrm{~m}^{2}$ is $10,801 \mathrm{kWh}$ by making an average investment of $€ 11,601$, thus saving $€ 2,961 /$ year with an average payback of 3.92 years.
\end{abstract}

Keywords: energy efficiency, healthcare centre, healthcare engineering, small healthcare facilities.

\section{INTRODUCTION}

It is estimated that in Spain the public health spending is about 63.8 billion euros, which represents $71.8 \%$ of the total health spending in the country. The total health expenditure in Spain is $8.5 \%$ of the GDP, public health expenditure represents $6.1 \%$ of the GDP and it is a cost per capita of $€ 1.421$ per year [1].

Public health is the largest enterprise both in number of workers and spending budget for many regions in Spain. The public sector employs more than one million people and manages a budget of almost $€ 60$ billion, an amount similar to total public spending in countries such as Ireland or Portugal [2].

Responsibility for health facility managers should extend beyond the control of the buildings and assume a more active role in aspects such as the management of energy and environmental emissions. It is necessary to establish measures of energy saving and

Corresponding author: Justo García-Sanz-Calcedo, Extremadura University, Department of Mechanical and Energetic Engineering. Avenida Santa Teresa de Journet 38, Badajoz, 06800, Spain. Phone: (34) 924-289-300. Fax: (34) 924-301-212. E-mail: jgsanz@unex.es. 
efficiency in all buildings sectors, including the healthcare sector. Within the healthcare sector, consumption on lighting alone amounts to approximately $1,000 \mathrm{GWh}$ per year, which represents $0.6 \%$ of the Spain electricity consumption and is responsible for the production of nearly 600,000 metric tons of $\mathrm{CO}_{2}$ each year [3].

In Extremadura, a region in the Southwest of Spain, healthcare buildings of Regional Health Service consume 22 billion kWh of electricity annually, 450,000 liters of diesel and $40,000 \mathrm{~m}^{3}$ of natural gas. These buildings emit 27,000 metric tons of $\mathrm{CO}_{2}$ and other greenhouse gases [4], providing care to a population of 1.07 million. However, the potential for energy savings from a healthcare centre [5] has not yet been studied in significant samples of buildings in Spain, where 2,956 healthcare centres were operational in 2010 [6].

Murray et al. (2008) showed that the smaller health service buildings in Scotland represented $29 \%$ of the total floor area of all buildings linked to the National Health Service of Scotland [7]. Santamaria et al. (1994) carried out a detailed analysis of audits for 30 health care buildings in Greece (Hellas) to quantify the potential global energy savings as $20 \%$ [8], hence suggesting possible savings of substantial energy in these buildings.

Vanhoudt et al. (2011) demonstrated that in a hospital in Belgium, it is possible to save up to $71 \%$ of the primary energy system by using thermal energy storage in combination with a heat pump compared to a gas-based boilers and water chiller [9]. Yun et al. (2012) demonstrated that a change in the occupancy patterns of a building with respect to the initial design settings might result in higher rates of energy consumption for lighting purposes, which can potentially reach a 50\% increase [10].

Martini et al. (2007) reported on the energy behavior of different types of health service facility of the Argentinian Public Health Network, and assessed correlations between energy consumption rates and a series of variables, i.e., space, use, infrastructure and equipment [11]. This involved evaluating the interactions among these variables and the energy consumption for each specialty service provided in the most common buildings, and detecting areas of over consumption and/or inadequate infrastructure.

Energy efficiency and energy use are major components of sustainability [12]. Specific measures to improve the energy efficiency of a particular building should consider climatic and local conditions, indoor climate environment [13] and amortization in terms of both economic and environmental aspects [14].

The present paper is aimed at analyzing and quantifying the average healthcare centres' energy behavior, as well as at estimating the potential savings through the use of concrete measures to reduce the energy demand in Extremadura, Spain.

\section{METHODS}

The energy consumption of 55 healthcare buildings was analyzed by using the data collected through audits carried out during 2005-2011 by the Extremadura Agency for Energy and financed through a collaborative agreement with the Ministry of Health and Dependence of Extremadura. The sample represents $52.38 \%$ of the healthcare centres and $42 \%$ of the population in the region. 
To ensure the homogeneity of the sample, 55 similar buildings were selected with respect to the heating system used (every one of the buildings uses a heat pump or a diesel boiler). The buildings selected had a floor area between 500 and 3,500 $\mathrm{m}^{2}$, and provided care to a population between 3,500 and 25,000. All buildings were constructed between 1985 and 2007 [15].

The energy audits include the use of instruments to measure energy use for the whole buildings and for energy systems within the building. In addition, computer simulation programs were considered to recommend energy retrofits for the facility.

To quantify the energy consumption in each building, scalar network analyzer and energy counters were installed. Field inspections to analyze the initial conditions and check the development of the measures implemented were performed. To determine annual consumption of water, gas and electricity, the billings from the supply companies were analyzed. The reactive power, the service water heating (SWH), the air conditioning systems, the lighting system, the external enclosures and renewable energy generation were also analyzed.

Equation 1 shows the evaluation of the annual savings achieved with the implementation of each of the tested measures.

$$
V=\left[\sum_{n=1}^{m}\left(E i_{n}-E f_{n}\right) \times C e\right]+g
$$

where $V$ is the achieved savings expressed in euros, $E i_{\mathrm{n}}$ is the annual energy consumption in $\mathrm{kWh}, E f_{n}$ is the estimated annual energy consumption after the application of the measure under test in $\mathrm{kWh}$ described in paragraph 3, Ce is the energy cost expressed in $€ / \mathrm{kWh}$, and $g$ is the application of taxes.

Values of the investment and the cost of energy were updated according to equations 2 and 3 to compare the potential savings provided for in each audit during the period from 2005 to 2011 .

$$
\begin{aligned}
& V e=C e \times(1+0.04)^{n} \\
& V a=C i \times(1+0.02)^{n}
\end{aligned}
$$

where $\mathrm{Va}$ represent the adjusted value for cost of investment $(\mathrm{Ci})$, Ve is the adjusted value for cost of energy $(\mathrm{Ce})$ and $n$ is the number of years. The values 0.02 and 0.04 derive from macroeconomic estimates of 2010 in Spain.

In the course of the investigation, certain parameters were identified in the relations between planned savings and other functional and operating costs of each healthcare centre, such as the year of construction, the construction area, the number of users and the service portfolio, using mathematical techniques. The empirical validity of the equations obtained from the study was tested applying the Student t-test for independent samples, using a confidence level of $95 \%$ in all cases. 


\section{RESULTS}

The percentages of the average distribution of the consumption of energy by end-use, can be seen in Figure 1, which shows that air conditioning and the heating system represent $50 \%$ of annual demand for energy from a healthcare centre [16], 30\% for lighting, $8 \%$ for hot water and $12 \%$ for the equipment.

Analysis of the average energy consumption demonstrates the existence of a correlation between the average final annual energy consumption and the built surface area in each healthcare centre. Dispersion of the sample diagram is depicted in Figure 2 , for a sample size of 55 .

The correlation is given by equation 4 below $\left(\mathrm{R}^{2}=0.9009\right)$ :

$$
C=107.31 S c-20,029
$$
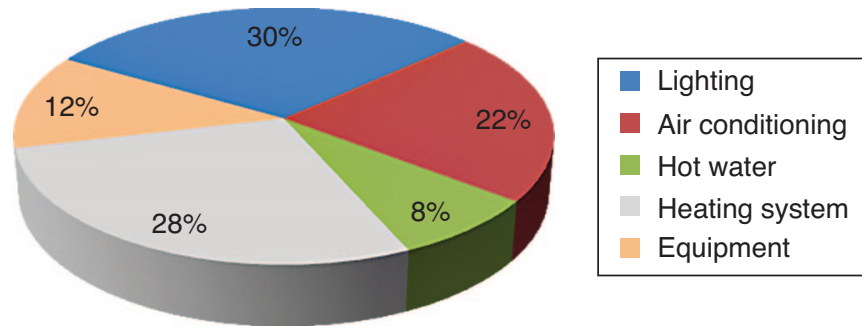

Figure 1. Distribution of annual energy demand for all fuels, by sector of consumption, in healthcare centres.

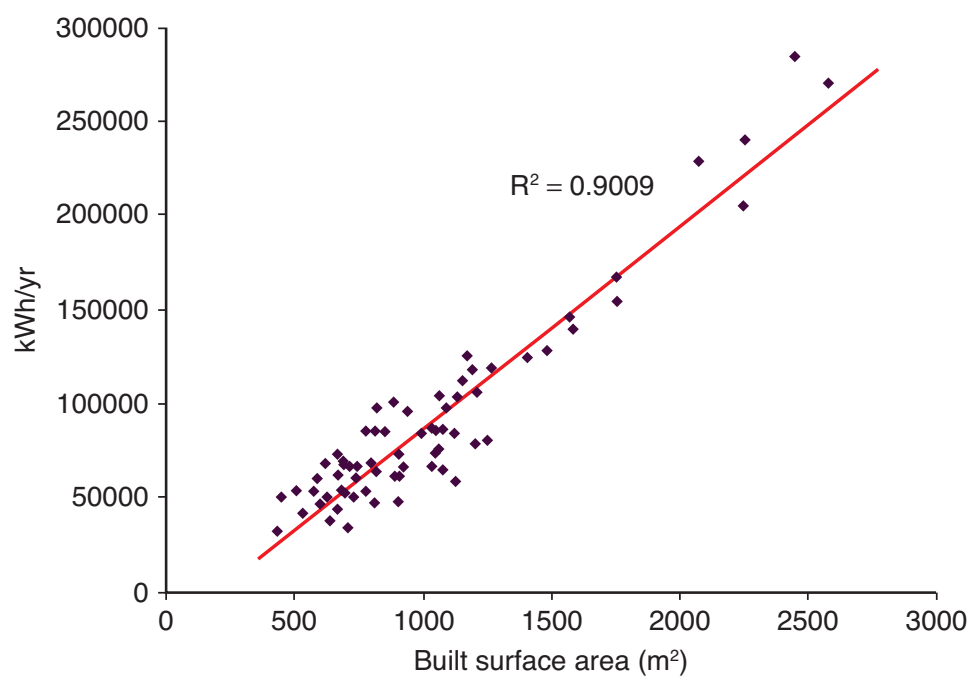

Figure 2. Relationship between the annual energy consumed and the built surface area in a healthcare centre. 
where $C$ is the annual consumption of final energy from the healthcare centre, expressed in $\mathrm{kWh}$ per year, and $S c$ is the built surface area in $\mathrm{m}^{2}$.

\subsection{The Reactive Power Compensation}

Devices such as motors or transformers involve magnetic fields and consume a so-called reactive power, causing drops in voltage, losses due to the Joule effect within wires, higher energy consumption and reduction in the availability of power and penalties in the electricity bill for their consumption [17]. The reactive elements can create voltage fluctuations and harmonic noise when switched on or off. They will supply or sink reactive power regardless of whether there is a corresponding load operating nearby, increasing the system's no-load losses. In the worst case, reactive elements can interact with the system and with each other to create resonant conditions, resulting in system instability and severe overvoltage fluctuations. To address this issue, installation of power capacitors is proposed. An automatic power factor correction unit consists of a number of capacitors that are switched by means of contactors. These contactors are controlled by a regulator that measures power factor in an electrical network. Depending on the load and power factor of the network, the power factor controller will switch the necessary blocks of capacitors in steps to make sure the power factor stays above a selected value.

The reactive power consumption in each building was obtained and the annual savings for each building was calculated as $0.86 € / \mathrm{m}^{2}$ with a standard deviation of $0.70 € / \mathrm{m}^{2}$. Moreover, the updated annual savings was correlated with the investment.

\subsection{Improvement in Service Water Heating}

Healthcare centres consume a large amount of domestic service hot water [18]. The average hot water consumption per healthcare centre was calculated as $450 \mathrm{liters} / \mathrm{m}^{2}$. In the case of production of hot water by means of water heaters, or storage tanks, timers with programmed disconnection can be installed in order to interrupt operation when no activity takes place. As regards the consumption of drinking water, the installation of low consumption taps and tanks with double push button is proposed.

Potential annual savings to an average of $€ 792.22$ per building under study was observed, which yields an annual savings $0.61 € / \mathrm{m}^{2}$, with a standard deviation of $0.51 € / \mathrm{m}^{2}$. This saving is determined by monitoring the water heating consumption for a year in healthcare centres.

\subsection{Improvement in the Lighting System}

Lighting for a typical healthcare centre represents on average $30 \%$ of the total electrical energy use. The installation of electronic ballast in fluorescent lamps, replacing fluorescent and incandescent lamps by others of higher performance (e.g., LEDs), organizing lighting according to activity type and limiting the intensity and timing of the control of lighting (by occupancy sensors) are some of the proposed solutions [19]. The adequacy of the parameters of lighting lamps to each unit and the increase of the maintenance of the lighting system were also analyzed.

In the course of the investigation, the updated annual savings was shown to be correlated to the investment. Such correlation is represented in Figure 3, and data were fitted to the following expression: 


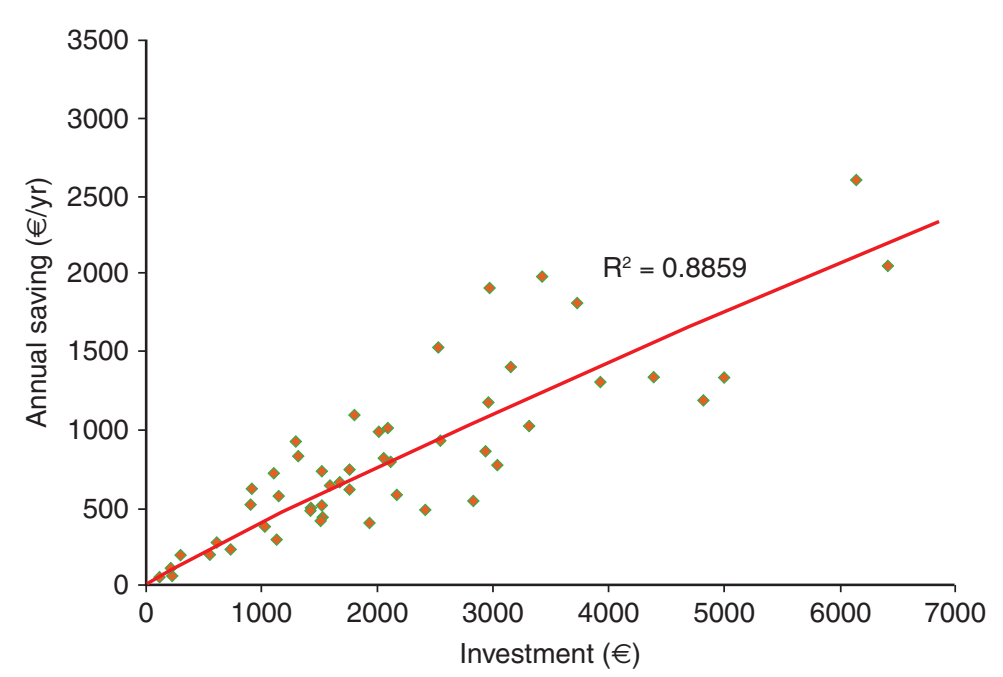

Figure 3. Correlation between investment and annual savings regarding the improvement of lighting systems in healthcare centres.

$$
E=0.754 i^{0.91}
$$

where $E$ is the annual savings from the healthcare centre and $i$ the required investment expressed in euros. This equation enables calculation of the average investment in lighting systems to ensure a given annual savings.

The average savings reached $€ 809.90$ per year for each of the buildings under study, which yields an annual savings of $0.73 € / \mathrm{m}^{2}$ with a standard deviation of $0.42 € / \mathrm{m}^{2}$. The involved calculations were performed by computer simulation software based on the performance of the luminaries and field inspections.

In addition to the reduction in total facility electrical energy use, retrofits of the electrical systems decrease space cooling loads and therefore further reduce the electrical energy use in the buildings [20]. These cooling energy reductions as well as possible increases in thermal energy use (for space heating) should also be accounted for when evaluating the cost-effectiveness in lighting equipment.

\subsection{Heating, Cooling and Ventilation Systems}

Heating, cooling and ventilation systems for a typical healthcare centre represents on average $50 \%$ of the total electrical energy use. The introduction of efficient air conditioning technologies that minimize energy consumption is proposed. $16 \%$ of the installed air conditioning devices had been operating for less than 5 years, $31 \%$ for a period in the range 5-10 years and the remaining $43 \%$ for more than 10 years. The replacement of low-performing machines aged more than 8 years by new, highperformance models was suggested. 
Other feasible measures to be carried out in this area are the following: maintenance of air-conditioning systems, zoning according to air conditioning units and installation of air-handling system adjustable thermostats [21].

Average annual savings was calculated to approach $€ 800.00$ for each of the buildings under study, which might also be expressed as $0.75 € / \mathrm{m}^{2}$, with $0.45 € / \mathrm{m}^{2}$ standard deviation. Calculations were performed based on a reference of the optimized efficiencies of some other air conditioning devices which had previously been analyzed.

\subsection{Measures on External Enclosures}

The improvement of the thermal insulation of the building enables to lower the heating/cooling loads [22]. The proposed measures include the following actions: increasing the insulation level of roofs [23], sealing doors and windows to prevent infiltrations, installing blinds to reduce direct beam solar radiation, installing overhangs, replacing single glazing with double glazing, and applying protective glazing films.

The main thermal losses in hallways, waiting rooms and corridors were observed to occur when access doors remained open, provided that the most usual type of access to healthcare centres consists of windshield partition doors, a system that loses effectiveness as doors might even remain open during the busiest periods in the building [24].

The average annual savings per sample building was computed by energy computer simulation as $€ 716.50$, which represents an annual savings of $0.68 € / \mathrm{m}^{2}$ with a standard deviation of $0.48 € / \mathrm{m}^{2}$.

\subsection{Renewable Energy Generation}

The replacement of conventional energy generation with renewable energy is recommended mainly because some renewables can become more profitable over time than conventional energy sources [25] and also because renewables are intrinsically linked to the concept of environmental sustainability [26].

The installation of biomass and solar thermal facilities was found to contribute with average annual savings of $€ 537.04$ per building under study $\left(0.55 € / \mathrm{m}^{2}\right.$ annual savings with standard deviation $0.42 € / \mathrm{m}^{2}$ ). It should be noted that the high initial costs associated to the installation of renewable equipments was accounted for in the above mentioned calculations. The potential renewable energy sources for the stated purposes are listed below:

a) Biomass: Replacement of heating boilers using fossil fuels, diesel or natural gas, with biomass boilers. The current biomass energy conversion technology ensures the efficient operation of the facilities [27]. Carbon dioxide emissions in the combustion of biomass are almost neutral, provided it is part of the base that the plant vegetable retains a higher volume of $\mathrm{CO}_{2}$ during its growth as compared with that released during combustion [28].

b) Solar thermal energy: Use of solar thermal energy for hot water generation allows reduction of energy consumption and decrease of greenhouse gas emissions. In smaller buildings, hot water demand is relatively low and 
therefore, the current systems usually do not use central distribution networks [29], provided such demand is satisfied by the electric hot water heater near the consumption points. Installation of solar collectors on roofs ensures a drastic reduction of energy consumption and is regarded as an efficient energy supply alternative. If larger buildings with higher associated energy consumption rates are accounted for, remarkable efficiency of solar thermal energy equipment has been reported [30].

c) Solar photovoltaic: It is fed into the public grid power generated by a photovoltaic field, allowing the production of electricity from solar energy. It is a performance that can serve to considerably lower energy cost and contribute to the overall decrease in emissions [31].

d) Geothermal energy: Use of low temperature geothermal energy is based on the fact that the ground below a depth of $7-10 \mathrm{~m}$ is maintained at a stable temperature, about $17^{\circ} \mathrm{C}$, regardless of time of year or weather conditions. This energy source allows to increase the performance of the air conditioning equipment and has been set as a renewable energy in Europe since 2009 [32].

\subsection{Optimization of Energy Billing}

To ensure a reduction of energy billing, the optimization of the contractual conditions with the electricity supply companies is suggested. The power of recruitment should be adapted to the actual consumption by selecting the best rate, by accounting for time discrimination and by taking advantage of opportunities of negotiation arising from the high energy demand associated to the buildings and the dynamism of market prices, in other words, by identifying opportunities derived from the scale economy [33] within the particular restrictions of current legislation.

If the above mentioned considerations are accounted for, the corresponding average annual savings is calculated as $€ 662.96$ per sample building. This rate was obtained from the average savings achieved in the audits performed and is equivalent to $0.59 € / \mathrm{m}^{2}$ annual savings with a standard deviation of $0.49 € / \mathrm{m}^{2}$.

\subsection{Results of Application of Measures}

The results for the application of the particular measures described in the preceding subsections are shown in Table 1.

Furthermore, Figure 4 depicts the payback time derived from each of the measures under consideration, while Table 2 lists the results regarding the quantification of their environmental impact.

Healthcare centres with greater potential saving rates - hence suggested for immediate implementation of the proposed energy saving measures - were identified as those built between 1990 and 2000, as shown in Figure 5 based on the mean of the average results reported in the audits.

\section{DISCUSSION}

Energy efficiency investments should be oriented to change the current trend of growth of energy consumption and to consolidate a culture of energy saving [34]. The results 
Table 1. Average savings due to application of energy saving measures

\begin{tabular}{lccc}
\hline Item & $\begin{array}{c}\text { Annual savings } \\
(€ / \mathbf{y r})\end{array}$ & $\begin{array}{c}\text { Annual savings } \\
\left(€ / \mathbf{m}^{\mathbf{2}}\right)\end{array}$ & $\begin{array}{c}\text { Investment } \\
(€)\end{array}$ \\
\hline $\begin{array}{l}\text { Energy billing } \\
\text { Reactive Power }\end{array}$ & 662.96 & 0.59 & 0 \\
Compensation & $1,332.23$ & 0.86 & $1,670.12$ \\
Service Water Heating & 792.22 & 0.61 & 299.23 \\
Heating, Cooling and & & & \\
Ventilation & 809.90 & 0.75 & $2,093.78$ \\
Lighting & 800.00 & 0.73 & $6,340.00$ \\
External enclosures & 716.50 & 0.68 & $4,544.00$ \\
Renewable energy & 537.04 & 0.55 & $4,853.93$ \\
Total & $5,650.85$ & 4.77 & $19,801.06$ \\
\hline
\end{tabular}

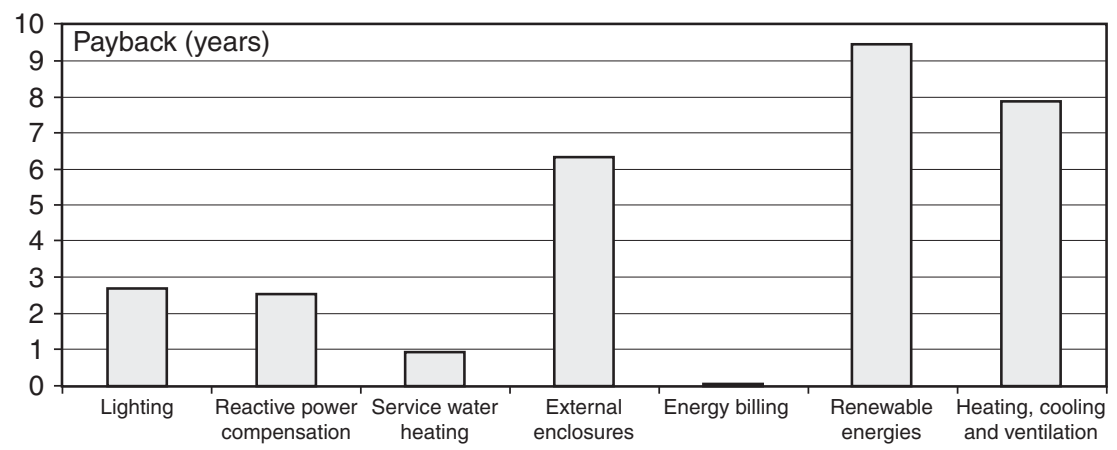

Figure 4. Average payback time for each of the proposed energy saving measures.

Table 2. Annual environmental impact.

\begin{tabular}{lc}
\hline Item & Value \\
\hline Healthcare buildings & 55 \\
Energy savings $(\mathrm{kWh} / \mathrm{yr})$ & 594.072 \\
$\mathrm{CO}_{2}$ savings $(\mathrm{kg} / \mathrm{yr})$ & 385.553 \\
$\mathrm{Particles} \mathrm{savings}(\mathrm{kg} / \mathrm{yr})_{\mathrm{SO}_{2} \text { savings }(\mathrm{kg} / \mathrm{yr})}^{26.276}$ \\
$\mathrm{NO}_{2}$ savings $(\mathrm{kg} / \mathrm{yr})$ & 4.087 \\
$\mathrm{CO}$ savings $(\mathrm{kg} / \mathrm{yr})$ & 220 \\
\end{tabular}




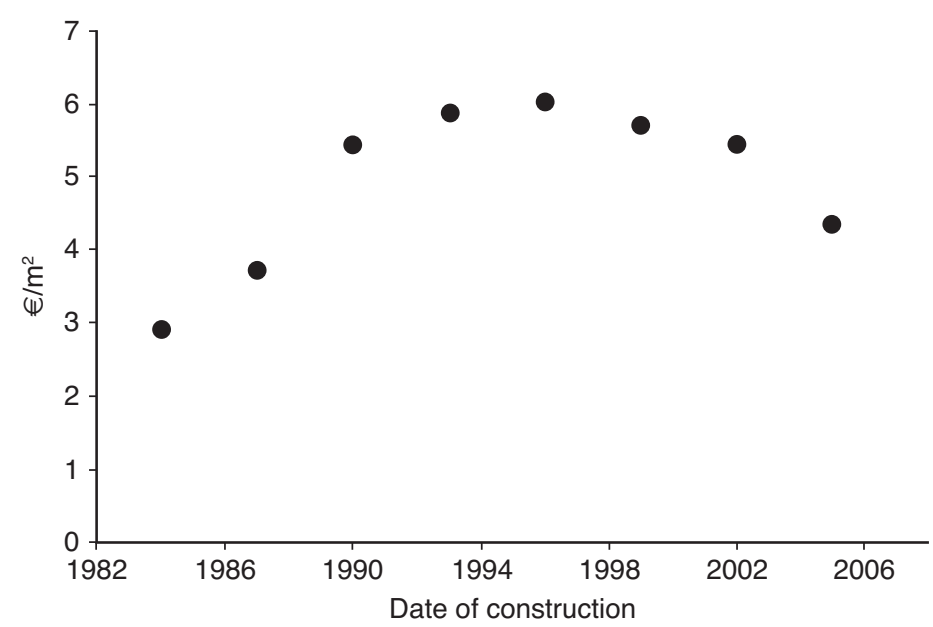

Figure 5. Average annual savings per built surface area vs. date of construction.

reported in this paper for the implementation of a set of energy saving measures on 55 healthcare buildings lead to a significant potential annual savings of $4.77 € / \mathrm{m}^{2}$.

Provided energy consumption is strongly linked to the management of the building users [35], it is strongly advisable to promote awareness-raising campaigns for energy saving actions, defining reasonable goals to enhance motivation, which preferably should involve changing users' habits, as it requires no investment, such as turning lights or computers off, and moderate use of air conditioning and heating systems. An energy audit is an appropriate tool to analyse energy costs and model the distribution of consumption. It allows identification of key parameters affecting energy consumption and assessment of various possibilities of energy saving based on profitability, thus enabling decrease costs of operation, maintenance and replacement. The energy and the environmental efficiencies should definitely be major quality indicators in the management of healthcare centres. Coherent selection of energy service companies for planning, implementation and financing of energy efficiency measures would improve the management of this type of public buildings and would also promote investment on efficient technology.

Potential cost savings was assumed by negotiating the price of energy. However, it should be noted that this is likely only in countries where price strategies are not set by the current normative and thus scale economy is allowed. On the other hand, given the particular nature of the issue under study, it should also be kept in mind that extreme strategies might result in fatal medical errors [36]: thermal discomfort or inadequate lighting levels might affect medical diagnosis [37] and appropriate measures for infection control might be directly affected by insufficient ventilation. Given the particular features of this type of public building, none of the energy saving measures can compromise health and performance of the users [38]. Potential consequences of 
extreme handling of energy saving measures should therefore be balanced out considering that the building performance should ensure aseptic conditions [39].

The results are extrapolated to similar buildings with limitations due to the wide variety of healthcare building designs mainly based on architectural conception, climate conditions, interior facilities and building locations.

\section{CONCLUSIONS}

The results reported in the present study lead to conclude that potential energy savings can be achieved in healthcare buildings smaller than $3,500 \mathrm{~m}^{2}$. A sampling set of 55 healthcare buildings was selected to undergo simulation of energy efficiency actions, which resulted in a final annual savings of $4.77 € / \mathrm{m}^{2}$. An average investment of $€ 11,601$ was estimated to potentially decrease energy consumption by $10,801 \mathrm{kWh}$ and to achieve annual savings of $€ 2,961$ (thus resulting in an average payback time of 3.92 years and avoiding the emission of $7,010 \mathrm{~kg} \mathrm{CO}_{2}$ ). Annual energy consumption was observed to decrease in efficiently managed buildings and to be more effectively implemented in small buildings rather than in those designed for a large number of users.

Measures to improve the energy efficiency of healthcare centres should account for weather conditions and local particularities, as well as for the inside environment and cost-effectiveness aspects. On another note, they should not break other essential requirements linked to this type of buildings, such as accessibility, supply security, and reliability of facilities. Assuming budgetary and the financial feasibility of the discussed measures, they should be prioritized according to the period of return on investment.

\section{ACKNOWLEDGEMENTS}

The author wishes to express his gratitude to the Regional Ministry for Health and Dependence of the Regional Government in Extremadura (Spain), as well as the National Institute for Health Management for the information provided for the present work, which was supported by Project GR 10099 from the Regional Government of Extremadura and the European FEDER funds.

\section{CONFLICT OF INTEREST}

The author indicates no potential conflicts of interest.

\section{NOMENCLATURE}

$C$ Annual consumption of final energy, $\mathrm{kWh} /$ year

Ce Energy cost, $€ / \mathrm{kWh}$

$\mathrm{Ci}$ Investment cost, $€$

$E$ Annual savings from lighting system, $€$

Ef Estimated annual energy consumption, kWh/year

Ei Annual energy consumption, kWh/year

$g$ Taxes, $€$

$i \quad$ Value of investment in lighting system, $€$

$n \quad$ Number of years, year 


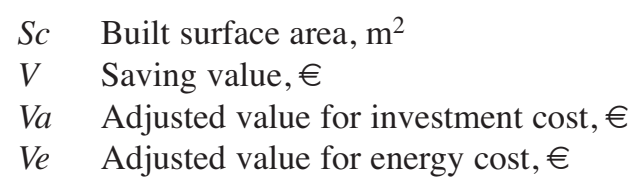

\section{REFERENCES}

[1] Ministry for Health, Social and Equality Policy. National Health System of Spain. Madrid 2010.

[2] Fundación de Estudios de Economía Aplicada (FEDEA). Impulsar un cambio posible en el sistema sanitario. McKinsey \& Company. 2009.

[3] IDAE. Guía Técnica de Eficiencia Energética en Iluminación. Hospitales y Centros de Atención Primaria. Idae, Madrid, 2001.

[4] García Sanz-Calcedo J, Cuadros F, López-Rodríguez F. La auditoría energética: una herramienta de gestión en Atención Primaria. Gaceta Sanitaria, 2011, 25(7):549-551.

[5] Garc'a Sanz-Calcedo J, López-Rodríguez F, Cuadros F. Quantitative analysis on energy efficiency of health centers according to their size. Energy and Buildings, 2014, 73:7-12.

[6] Ministry for Health, Social and Equality Policy. Catalogue of Primary Care Centres of the National Health System. Madrid, 2011.

[7] Murray J, Pahl O, Burek S. Evaluating the scope for energy-efficiency improvements in the public sector: Benchmarking NHS Scotland's smaller health buildings. Energy Policy, 2008, 36(3):1236-1242.

[8] Santamouris M, Dascalaki E, Balaras C, Argiriou A, Gaglia A. Energy performance and energy conservation in health care buildings in Hellas. Energy Conversion and Management, 1994, 35(4):293-305.

[9] Vanhoudt D, Desmedt J, Van Bael J, Robeyn N, Hoes H. An aquifer thermal storage system in a Belgian hospital: Long-term experimental evaluation of energy and cost savings. Energy and Buildings, 2011, 43:3657-3665.

[10] Yun G, Kim H, Kim JT. Sustainable and healthy buildings. Effects of occupancy and lighting use patterns on lighting energy consumption. Energy and Buildings, 2012, 46:152-158.

[11] Martini I, Discoli C, Rosenfeld E. Methodology developed for the energy-productive diagnosis and evaluation in health buildings. Energy and Buildings, 2007, 39(6):727-735.

[12] Bonnema E, Pless S, Doebber I. Advanced Energy Design Guide for Small Hospitals and Healthcare Facilities. Journal of Healthcare Engineering, 2010, 1(2):277-296.

[13] Bizzarri G, Morini GL. New technologies for an effective energy retrofit of hospitals. Applied Thermal Engineering, 2006, 26: 161-169.

[14] Yoshida S, Koichi I, Yokohama R. Sensitivity analysis in structure optimization of energy supply systems for a hospital. Energy Conversion and Managemōent, 2007, 48-11:2836-2843.

[15] Ferrer JL, Peral D. El Centro de Salud. Su evoluci-n en Extremadura. Revista de Estudios Extreme\&ntilde;os, 2007, 63:73-104.

[16] Sartori I, Hestnes AG. Energy use in the life cycle of conventional and low-energy buildings: A review article. Energy and Buildings, 2007, 39:249-257.

[17] Shohet IM. Building Evaluation Methodology for Setting Maintenance Priorities in Hospital Buildings. Construction Management and Economics, 2003, 21:681-692.

[18] Garc'a Sanz-Calcedo J. Anáisis sobre la sensibilidad energética y medioambiental de los parámetros funcionales en los Centros de Salud de Extremadura. Tesis Doctoral. Universidad de Extremadura, 2009.

[19] Guenther R, Vittori G. Sustainable Healthcare Architecture. Ed. Wiley, 2013.

[20] Moncef Krart. Energy Audit of Building Systems: An Engineering Approach, Second Edition. Taylor \& Francis Group. 2011.

[21] Szklo AS, Soares JB, Tolmasquim MT. Energy consumption indicators and CHP technical potential in the Brazilian hospital sector. Energy Conversion and Management, 2004, 45:2075-2091. 
[22] Thormark C. A low energy building in a life cycle its embodied energy, energy need for operation and recycling potential. Building and Environment, 2002, 37:29-435.

[23] Santamouris M. Natural cooling techniques in proceedings of the workshop on passive cooling. Joint Research Centre. Ispra, 1990, 12:143-153.

[24] Congradac V, Prebiracevíc B, Jorgovanovíc N, Stanisic D. Assessing the energy consumption for heating and cooling in hospitals. Energy and Buildings, 2012, 48:146-154.

[25] Sevilla M, Golf E, Driha OM. The Renewable Energy in Spain. Estudios de econom'a aplicada, 2013, 31(1):35-58.

[26] Daura J. Mejora de la eficiencia energética en instalaciones industriales y edificios. Anuales de mecānica y electricidad, 2007, 4:34-38.

[27] García Sanz-Calcedo J, Cuadros F, López F. Efficiency of a biomass boiler in a hospital center. Use of olive crushing stones to produce heat. Dyna, 2011, 86(3):343-349.

[28] Idae. Condiciones de aceptación de procedimientos alternativos a LIDER y CALENER. Anexos. Madrid, 2009.

[29] Romero M. La eficiencia energētica en edificios sanitarios de dimensiones reducidas. Todo Hospital, 2009. 260:613-620.

[30] Gallardo M, Rubio-Recio JM. Sistemas solares térmicos con acumulación de inercia. Era solar, 2012, 168:6-16

[31] Mccormick M, Shepley M. How Can Consumers Benefit from Therapeutic Environments? Journal of Architectural and Planning Research, 2003, 20:4-15.

[32] European Union. Directive 2009/28/EC on the promotion of the use of energy from renewable sources. 2009.

[33] Aranda A, Scarpellini S, Feijoo M. Análisis de la eficiencia energética en la industria española y su potencial de ahorro. Economīa industrial, 2003, 352:11-24.

[34] Malin N. Closing the Feedback Loop: Demand for Proof-of-Performance Claims Plus increasing Designer Confidence Lead to an Evidence-Based Design. The Magazine of Sustainable Design, 2007, 15:13-24.

[35] García Sanz-Calcedo J, Cuadros F, López-Rodríguez F. Influence of the number of users on the energy efficiency of health centres. Energy and Buildings, 2011, 43(7):1544-1548.

[36] Hedge, A. Indoor Environmental Quality, Health and Productivity. Indoor Work and Living Environments. Ed. Moore, DP. New York, 2009.

[37] Buchanan TL, Barker KN, Gibson JT, Jiang C, Pearson RE. Illumination and error dispensing. American Journal of Hospital Pharmac, 1991, 48(10):2137-2145.

[38] Shepley M, Baum M, Ginsberg R, Rostenberg W. Eco-effective design and evidence-based design: perceived synergy and conflict. Health Environments Research \& Design Journal, 2009, 2(3):56-70.

[39] Shepley M, Baum M, Rostenberg B. A collaborative research project on evidence-based and ecoeffective design. ARCC Journal, 2009, 6(2):81-87. 



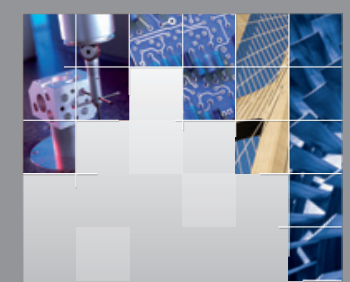

\section{Enfincering}
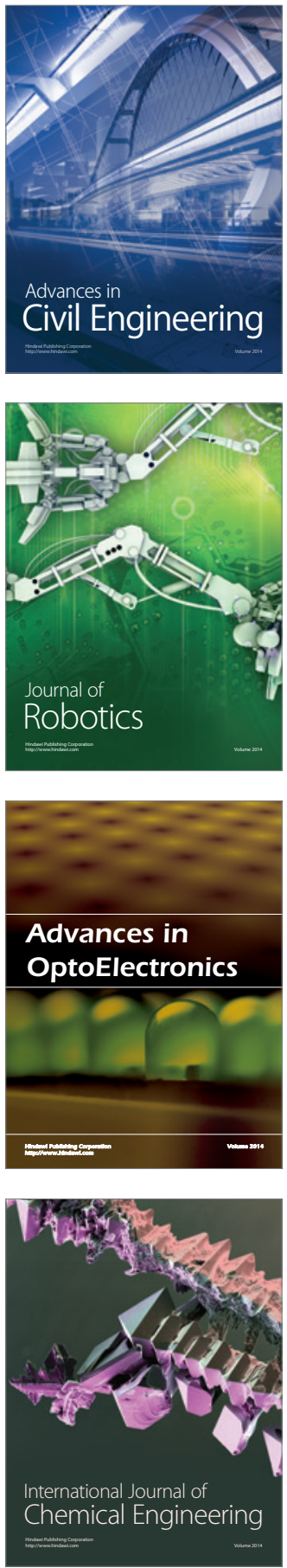

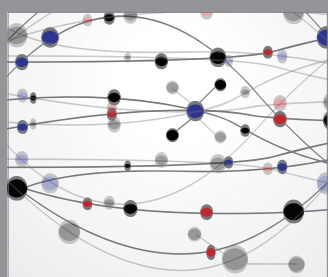

The Scientific World Journal

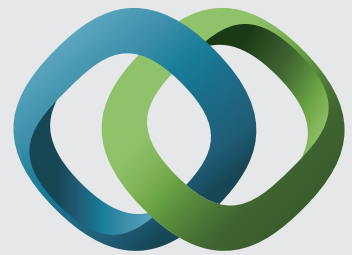

\section{Hindawi}

Submit your manuscripts at

http://www.hindawi.com
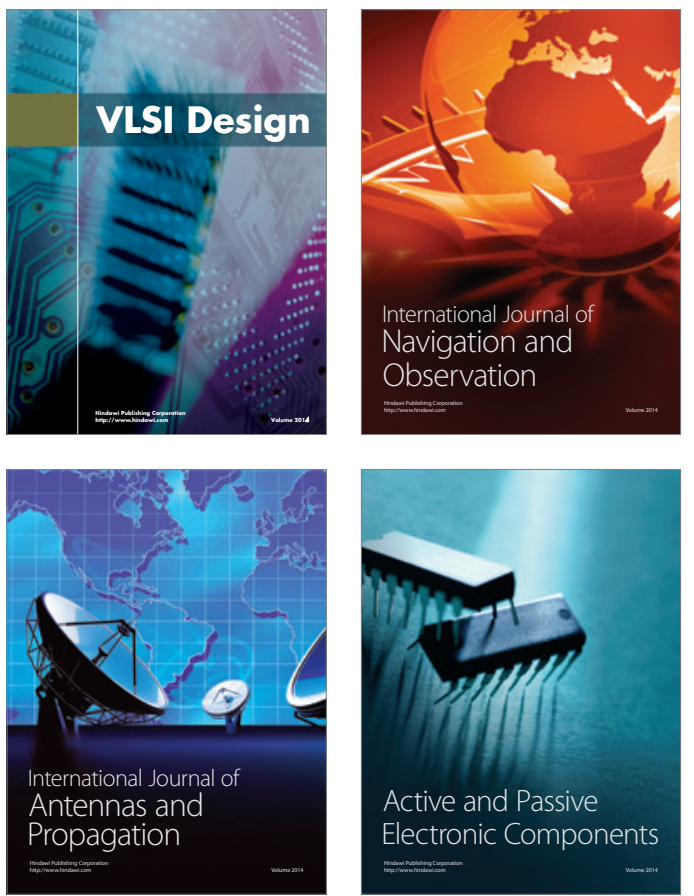
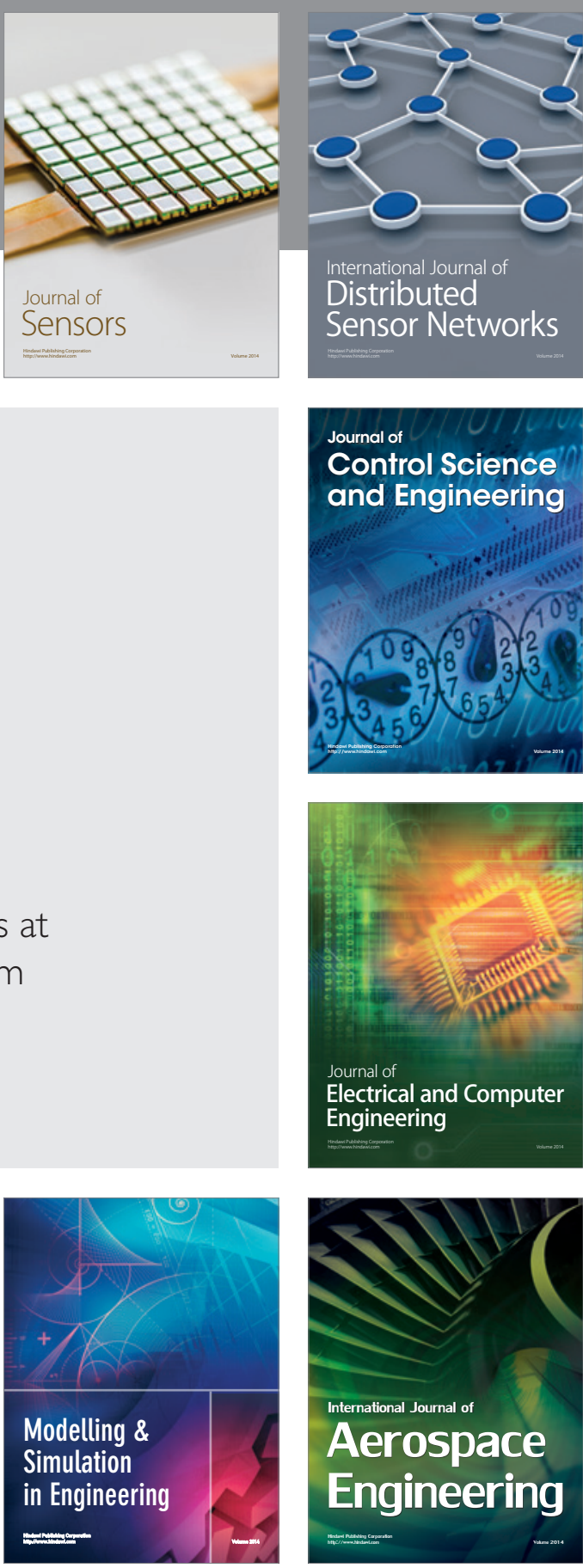

International Journal of

Distributed

Sensor Networks

Journal of

Control Science

and Engineering
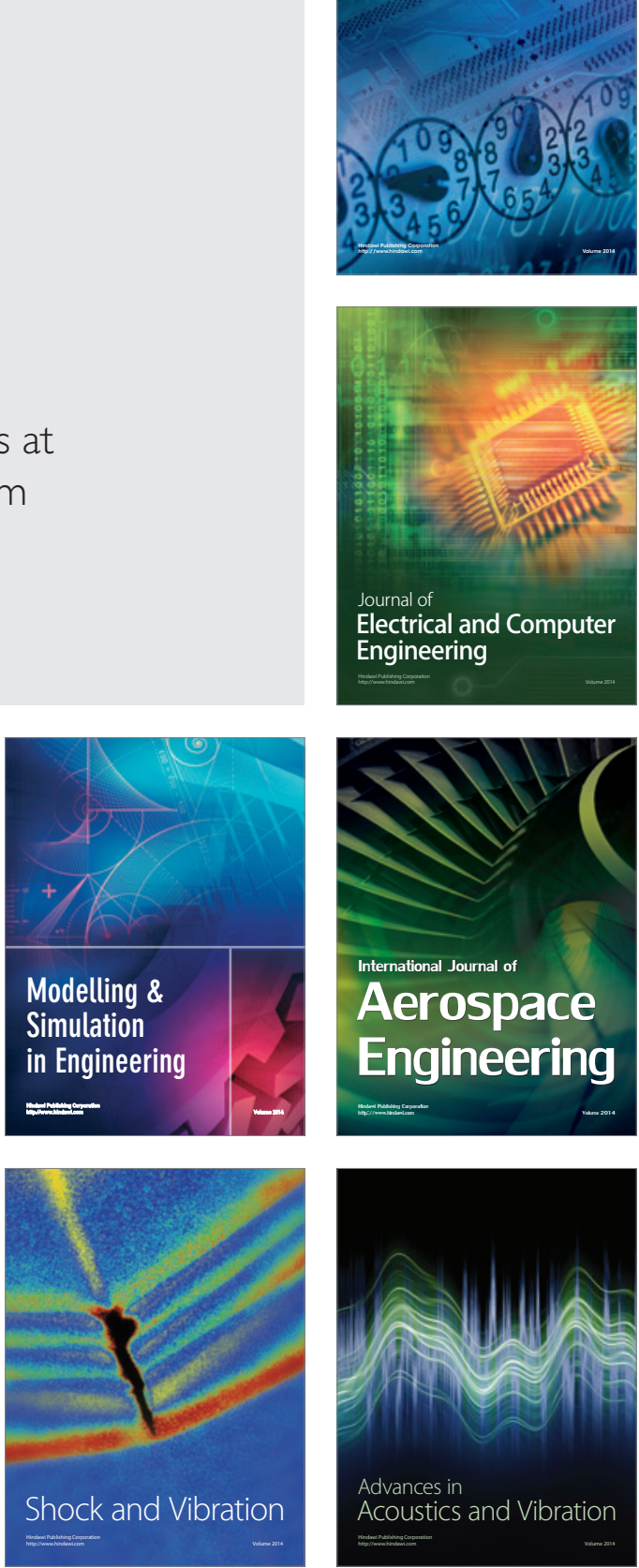